\title{
Why do Scientists Migrate? A Diffusion Model
}

\author{
Dietmar Braun
}

Published online: 9 November 2012

(C) Springer Science+Business Media Dordrecht 2012

\begin{abstract}
This article improves our understanding of the reasons underlying the intellectual migration of scientists from existing cognitive domains to nascent scientific fields. To that purpose we present, first, a number of findings from the sociology of science that give different insights about scientific migration. We then attempt to bring some of these insights together under the conceptual roof of an actor-based approach linking expected utility and diffusion theory. Intellectual migration is seen as the choice of scientists who decide under uncertainty and on the base of estimations about probabilities, costs, and benefits of the migration. The resulting choice model can be used as a heuristic base for further exploration of the subject.
\end{abstract}

Keywords Scientific innovation - Theory · Diffusion

\section{Introduction}

An essential part of understanding innovation processes is to know how a scientific discovery becomes part of the scientific canon, or said differently, how a new scientific idea is diffused within the scientific community and becomes institutionalised as a new scientific field.

Our main interest in this article is to understand an essential part of this process: the diffusion of scientific inventions would be impossible if there were no scientists being prepared to migrate from existing fields of knowledge to new ones. Migration of scientists means to embrace new ideas, artefacts, methods, or practices that are still relatively unknown and uncertain in their working and make them the base of

D. Braun $(\bowtie)$

Institut d'Etudes Politiques et Internationales, Université de Lausanne, Géopolis,

1015 Lausanne, Switzerland

e-mail: Dietmar.Braun@unil.ch 
future research activities. It means the willingness to switch from research activities in established disciplines, specialties, subspecialties or established research areas to research activities in cognitive areas still in exploration and development. Though it seems as if this would be "normal" scientific procedure, one cannot assume that scientists will migrate without thinking twice. They are socialised in certain disciplines and specialties; they have invested in a knowledge domain, often for a considerable time; their networks are built around the cognitive field they are mastering; and their reputation is constructed on the base of their achievements in the existing field. Intellectual migration means accepting uncertainties about future positions and scientific recognition. This is why it is worthwhile to look deeper into the conditions that explain migration or non-migration of scientists into new and unexplored fields. A coherent theoretical framework that can serve as a heuristics for hypothesis development and empirical research is still lacking.

In order to advance on this point, one can build on various insights from the sociology of science dealing with "scientific growth", the cognitive and academic development of science. These insights will be presented in the following section. It turns out, however, that these insights remain fragmented and do not add up to a coherent approach. It is our concern in this article to bring these insights together and link them to a model of decision-making of scientists about scientific migration (section "A Choice Model of Scientific Migration"). Diffusion theory will then be used to explain how individual decisions of scientists can add up to a collective process of scientific migration to new fields (section "Diffusion”).

\section{Insights from the Sociology of Science}

One can distinguish three broad approaches to conceptualise the choice situation of scientists when being confronted with new developments: the "cognitive" approach with a view of the scientists as an "epistemic agent"; the "reputational approach" underlining the unlimited competition of scientists and the vision of scientists as "reputation-seekers"; and, finally, the "invisible college" approach stressing the cooperative and social elements in scientists' decision-making. Each approach is not built on one coherent theoretical device but the studies share a number of basic assumptions and interests in explaining the choice situation in science. Our aim in this paper is to demonstrate that these approaches are not mutually exclusive but that the different elements they emphasise can be brought together under one conceptual roof furnished by expected utility theory.

\section{Cognitive Dynamics and "Epistemic Agents" Matter}

Approaches highlighting the cognitive aspects of scientific development see scientists above all as "epistemic agents" looking for opportunities to develop new ideas.

Scientists as epistemic agents are intrinsically driven to do research because it gives them intellectual satisfaction. They are curious by nature and love to explore new opportunities. Such a vision of the scientist can be found throughout the 
different contributions to the sociology of science. More recently, Lamont stressed "pleasure and curiosity" as a primordial motivation in scientists' decisions (Lamont 2010). Manathunga discovers in her study the "intense emotional and intellectual rewards" that influence the decision of scientists to go into interdisciplinary areas (Manathunga 2009). Akerlind, finally (Åkerlind 2008), has, on the basis of several studies, found "self-development" as one of four personal motivations of scientists. "There is a primary focus on satisfying the researcher's curiosity and enhancing their personal understanding of an issue, with accompanying feelings of enthusiasm and interest in the research" (ibid.: 26). These authors do not deny other motivational drives but intellectual satisfaction out of scientific discovery is certainly a primary one in cognitive development.

Epistemic agents seize cognitive opportunities when they can. The literature on cognitive dynamics is above all directed to the different structures and dynamics of the cognitive field of science that are at the root of such opportunities.

Holton (1962), for example, proposes a model in which scientific fields consist of a limited stock of available "ideas" that scientists can use. New and unexplored fields offer plenty of occasions for scientists to satisfy curiosity, as the stock of ideas is still full. These occasions diminish the more scientists enter into this field. The stock of available ideas becomes gradually depleted. This is the time to look for other unexplored fields that, however, build on the existing one. Migration takes place (see similarly also Edge 1990).

Others, like Ben-David (1991), see scientific development as a constant differentiation of knowledge fields generated as a consequence of an ever-increasing stock of knowledge. The complexity of available knowledge leads scientists to find specialised topics and proliferate the paradigm in new contexts. Migration in this case is the result of knowledge "overflow" and not of knowledge depletion.

Bonaccorsi recently argued in a similar way $(2007$; 2008). While scientists may adhere to same underlying paradigms, they "still diverge on more specific theories that link this causal explanation to the various levels of organization of life". The result is again a "proliferation of specialized sub-theories". "Divergence" is one of the main characteristics of the "new sciences" like nanotechnology or biotechnology.

Based on ideas of Kuhn (1968), "finalisation theory" distinguished different phases of cognitive development. Above all in the "pre-paradigmatic phase", scientists are attracted by the rise of a new paradigm and migrate to new fields, while it is the "postparadigmatic" phase, in which openness to "external" influences leads scientists to specialise by applying their paradigm to an increasing number of different contexts (van den Daele 1977; Weingart 1997).

These authors are united in the belief that the migration of scientists to new fields of science is closely linked to the dynamics of cognitive structures. The search for new knowledge opportunities drives the "epistemic agent" to conquer new fields by migration.

\section{The "Strong Programme” and Scientific Migration}

The other approaches fit into a conceptual vision based on what Bloor (1976) and others have called the "strong programme" in science which emphasises social and 
cultural elements in the determination of what scientific "truth" is. Cognitive dynamics alone cannot explain scientific innovation and the scientist as an epistemic agent is questioned. In our context, one can distinguish two lines of reasoning: approaches that highligt competition and reputation seeking and those which stress cooperation and communication as determinants of scientific migration.

\section{Competition and Reputation Seeking}

This line of reasoning discusses scientific innovation by treating scientists above all as "reputation seekers" rather than epistemic agents. In this case, scientists, motivated by the search for "reputation", enter into competition for the distribution of reputation value. Latour and Woolgar have sketched scientific action as a "credibility cycle" based on reputation, which is - if successful - rewarded by material advantages, which is again the base for further reputation seeking (Latour and Woolgar 1979). As scientific reputation depends on the creation of new knowledge, seeking reputation generates permanently new knowledge and therefore scientific innovation.

Bourdieu has sketched scientific action as a continuing "struggle" for power, which is based on reputation (or, in his terminology, "scientific capital") (Bourdieu 1975; Clark 1995; Kogan 2000; Whitley 2000; 2001). The "champ scientifique" is subdivided into those who dominate and those who are dominated. Scientific innovation is possible according to this concept because there is an incentive for those who are dominated or who are still low in the social hierarchy to find cognitive fields with a low number of competitors. This incentive pushes the "dominated" to seek for unexplored fields in science. Newcomers to science or to a scientific field that is already "taken" have a similar motivation. They can either try to follow the usual steps to build a career and climb up the social ladder within the scientific field or "subvert" the power of the dominant "class" in this field by offering new paradigms and thereby challenge established knowledge. These scientists are therefore driven to go into new and unexplored fields because of competition.

Chubin develops similar ideas when underlining the importance of "marginal scientists" with "weak ties" in the scientific community for expanding the frontiers of knowledge (Chubin 1976). This kind of scientist is less prone to the conservative cognitive attitudes of the scientific establishment. Being a "newcomer", a "heretic" or "marginal" allows overcoming the existing "conservatism" of established scientists (see also Dogan and Pahre 1990).

Ben-David speaks of "forerunners" instead of marginal scientists. He introduces in addition the type of "founders". Founders have high scientific recognition and are willing to build up new cognitive fields from the scratch together with "followers", i.e. disciples, who decide to leave the scientific field they are working in because new fields offer better competitive conditions (Ben-David 1965).

All these authors accept competition and reputation seeking as the underlying driving mechanisms of cognitive development. The scientists who migrate often have a particular position as "marginal scientists" or "newcomers" reflecting their vulnerable position in the scientific competition for reputation. 


\section{Invisible Colleges}

Another strand takes in a decidedly different stance with regard to the kind of scientists that are at the base of innovation. They underline, contrary to the authors above, cooperation and communication in scientific fields within social circles as the base for scientific migration. The networks of "scientific elites" - or of "invisible colleges" (De Solla Price 1963; 1971; Crane 1972) or still "core groups" (Fuchs 1993) - are responsible for the shifting of cognitive frontiers instead of "marginal scientists". These elites, which are nevertheless striving for reputation, are in direct contact with each other, which leads to quick information flows and communication. "Non-elite groups" or "followers" are less prone to the search for reputation but are motivated by the search for a sufficient material base for continuing their work. They take up the ideas developed by elites and transform them into "normal science" by testing them and building up a teaching canon that is at the base of specialties and disciplines. The "authority" of scientific elites based on excellence and social networks, makes it easy to convince "followers" of the value of migration. The stronger those networks are and the more authority the elite has, the more rapid the diffusion of innovative knowledge takes place and the more widely diffused the new ideas become.

In contrast to the other strand, the authors stressing the role of invisible colleges do not see elites as the conservative establishment but as a particular group of top scientists who are able to gather most of the attention in the scientific field. The migration of scientists is therefore seen as a multi-stage process, in which scientific elites conquer new fields of knowledge and particular types of social relations authority and networks - are responsible for the diffusion of these new fields.

The authors within this strand base their insights strongly on the diffusion theory of Rogers (1995), which was originally published in the beginning of the 1960s. Rogers analysed a large number of innovations in history and tried to find common underlying mechanisms. We will come back to diffusion theory later on.

More recently, Frickel and Gross (2005) have attempted to formulate a more integrative theory of migration or, in their terms, of "scientific/intellectual movements", which combines elements of the cognitive and social approach to science. They limit their field of interest to those "movements" that arise as a "protest movement" against established paradigms, discarding other possibilities of specialty or sub-specialty creation or of the construction of interdisciplinary fields. For them the motivation of scientists has two origins: it is certainly based on "structure", the struggle for reputation in a competitive environment. But it is also based on "grievance" and "dissatisfaction" with existing knowledge. Scientists migrate because their intellectual aspirations are not met by the field (ibid.: 210). For them - but this has also already been underlined by Lamont or Akerlind (see above) - scientists have a multi-dimensional motivation structure. The epistemic agent lives comfortably together with the reputation seeker. They add, however, two other interesting elements to the discussion: One is their account of motivation and behaviour of the scientific elite. For them, these elites can exactly become "innovators" because they "enjoy a type of access or freedom that others in the field do not" have. They are "expected to present weird ideas; they are freed from 
normative constraints and encouraged to be playful and creative" (ibid.: 212), among others because they are established and do not risk anymore to become sanctioned. Not marginalists but elites are the ones that can work at the boundaries of existing knowledge. The second point is that science and scientific migration need resources and opportunities to develop. Money and employment and the institutions managing these resources play a critical role for success.

Frickel and Gross have pointed to the need of finding a more integrative theory of scientific migration. The strength of their argument is that they demonstrate the possibility of combining different causal elements discussed in the literature on scientific migration. The literature usually has stressed one or the other of these elements in putting forward their arguments discarding other elements from the causal matrix. Like Frickel and Gross, we believe that the numerous studies presented above indicate the causal importance of the various elements (like intellectual curiosity, reputation seeking, the structure of cognitive fields etc.) and that there is no need to put all explanatory value on only one variable. The problem is, however, how to combine these elements in such a way that we understand the relative value of each variable in decision situations with regard to scientific migration. Frickel and Gross stress the conjunction of different elements but fail to explain whether there is a rank-ordering of elements or if all elements have an equal role, to what extent situational factors matter in comparison to motivational elements, or how different career stages change the causal model. What one needs, therefore, is a concept to grasp at the interplay of these different elements.

\section{A Choice Model of Scientific Migration ${ }^{1}$}

We conceptualise migration of scientists as a choice situation: the researcher must decide if or if not he or she will take the step of working in a newly developing scientific field. On what decision-making variables will the researcher base his or her decision?

Our choice model is - as Kitcher's (1995) - based on expected utility theory, meaning that the researcher is seen as a "rational" actor (Braun 2003) who acts under uncertainty about the outcome of his or her actions. This is the reason the researcher must assume probabilities that a certain event may take place or not (Esser 1993).

We start by identifying the "expected utility function" of scientists that we see composed, on the one hand, of the "pay-offs" a certain investment will bring to the scientist and, on the other hand, of the "effectiveness" of the investments linked to migration.

Pay-Offs

The "pay-offs" for scientists are determined on the base of two assessments: first, by looking - following the "competition" approach - at the likely increase in reputation migration can bring to the scientist and, second, by judging on the resources that can be

\footnotetext{
${ }^{1}$ The general model was first developed together with Fabrizio Gilardi in the context of policy change and diffusion (Braun and Gilardi 2006).
} 
expected for doing research in the case of leaving the existing field. Reputation and resources - or in the terminology used by Bourdieu "scientific capital" and "economic capital" - are, as demonstrated by Latour and Woolgar, the two components of the "credibility cycle" scientists are involved in (Latour and Woolgar 1979). We assume that the interests of scientists are to gain as much reputation as possible and to have a maximum of resources at their disposition in order to do research.

Expected returns in terms of reputation in the new field are compared with the field the scientist is working in at the moment. A higher expected return of reputation in the new field will contribute to a positive decision about migration.

There are different kinds of resources scientists would hope to get for their research work when reflecting about going into a new area like for example having more time for doing research or dispose of a better infrastructure. We think that "employment prospects" are most of the time the main variable scientists take into consideration when determining the pay-offs of migration. The estimation of the value of employment for the scientist depends on his or her employment situation in the old field. Some researchers have tenure and any investment into a new scientific field may not result in a risk in losing the employment. Others, especially younger scientists, may not yet have any secure employment position. Investments into a new scientific field need therefore clear prospects of getting a paid salary.

In sum, both reputation chances and resource prospects are essential elements in determining the utility function of the scientist. Together they define to an important part the propensity for switching research domains. The chances that a scientist will invest into the new area are high when expectations about reputation and resource gains are positive. They remain high as long as either expectations from reputation gains or from resources are strong enough to outbalance possible negative effects on the other side. In other words, the researcher might still migrate if he or she calculates that the investment will make him or her much more famous than before in the scientific community even though resources taken together might actually decrease in comparison to the status quo. For example, a new employment position may have a lower salary or the infrastructure is worse than before etc. And this also holds vice versa.

If we want therefore to include resources in the utility function together with reputation, one must add weighting factors for each part. This means that the scientist can value reputation and resource gain differently depending on his or her individual dispositions and contextual conditions. The overall value given to utility is therefore composed of the relative weight given to reputation in relation to the relative weight given to resources. The following formula summarises these conclusions.

$$
\mathrm{Ui}=\mathrm{wRi}+(1-\mathrm{w}) \mathrm{RESi} ; \quad 0 \leq \mathrm{w} \leq 1
$$

where $\mathrm{Ui}$ is the pay-off for scientist $\mathrm{i}$; $\mathrm{w}$ is a weight factor; $\mathrm{Ri}$ is the expected reputation in the area for scientist $i$; RESi is the expected employment gain in the area for scientist i.

\section{Effectiveness}

The literature on the cognitive dynamics of science but also in part the literature on the social dynamics of science has pointed to the importance of scientific discovery 
and cognitive advancement for scientists. We believe that this part of scientists' life and motivation should not be left out of the decision formula. Scientists are not only "reputation-" and "resource-" maximising but they are also "epistemic agents" with profound and genuine interests into scientific advancement of knowledge.

This aspect of epistemic curiosity should be integrated by the notion of "effectiveness": the researcher must, in order to invest into a new field, also be convinced that he or she will find better solutions for scientific problems than before. The existing concept, theory, method or practice may yield a certain amount of satisfactory answers to a given problem. This certain amount can be called the "effectiveness" of a research theory, concept, method or practice (identified by a parameter " $\mathrm{m}$ "). But the effectiveness can be contested by alternative theories, methods, and promising discoveries in new fields of science.

Effectiveness is part of expected utilities of scientists. In this way the decision formula can be extended in the following way.

$$
\mathrm{EU}(\mathrm{i})=\mathrm{mUi} ; \quad 0 \leq \mathrm{m} \leq 1
$$

where EUi = expected utility of scientist in the existing field; $\mathrm{m}=$ effectiveness of existing theory, concept, method, practice; Ui is the pay-off for the scientist composed of the elements reputation and resources within the existing field.

Summing up, the expected utility function in the scientific field the scientist is actually working in consists of the pay-offs in terms of reputation and resources, on the one hand, and of the effectiveness of existing theories, methods etc., on the other. Both parts are not independent from each other: the overall expected utility will be lower if the effectiveness of the existing knowledge is not satisfying and it is also lower if reputation expectations in the existing field are low because of, for example, strong competition by other scientists. The overall expected utility is therefore the product of reputation and resource expectations, on the one hand, and effectiveness, on the other.

If we now want to integrate the comparative aspect that is at the base of the final decision of scientists to migrate into the model, we must imagine that a similar expected utility function exists with regard to the new scientific field under discussion.

$$
\mathrm{EU}(\mathrm{j})=\mathrm{nUj} ; \quad 0 \leq \mathrm{n} \leq 1
$$

where $E U(j)$ is the expected utility of a scientist in the new field; $n$ is the effectiveness attributed to the alternative new field and $\mathrm{Uj}$ is the pay-off function associated with the new field.

The scientist is put before the choice of accepting the status quo option, i.e. to remain a "member" within the existing scientific field, or to opt for a research career in the new field. This new field is then screened for its possible pay-offs and its effectiveness and put into comparison with the expected utility and effectiveness of the status quo. In order to go into the new field the following condition must hold:

$$
\mathrm{EU}(\text { change })=\mathrm{nUj}>\mathrm{mUi}
$$

A decreasing " $\mathrm{m}$ " will, for example, initiate search behaviour of the scientist in quest for better alternatives, even though utility may remain unchanged (reputation 
and resource expectations from the existing position). And the expected utility of a scientist can remain high even though reputation or resource expectations may decrease as long as " $\mathrm{m}$ " remains very high and compensates this loss or, in other words, if the existing way to find scientific solutions is satisfactory and no better alternatives are visible.

The chance for migration of scientists are, on the base of what has been said until now, high if the new scientific field

- generates expectations of higher reputation gain than in the case of a stay in the existing field;

- increases the expectations concerning resources, above all employment conditions;

- seems to have more promising answers to research questions

Costs

The expected utility of a new scientific field compared to the expected utility of the existing field is not sufficient in order to understand the decision rationale of scientists. Until now we have discussed the likely benefits of scientific action. Costs are the other side of the coin and must be integrated into the decision-making formula.

There are three kinds of costs the scientist has to take into account when deciding about entry into a new scientific field: cognitive, social, and material.

\section{Cognitive Costs}

Cognitive costs are most important in the decision-making of the scientist. They are generated when the scientist has to learn new concepts, theories or methods and apply them. The more "distant" the available knowledge of the scientist is with regard to the new theory etc., the more time investment it needs to overcome this cognitive distance. In other words, the closer the new scientific field is to the existing field the scientist is working in, the lower are the cognitive costs of transition.

\section{Social Costs}

Similar considerations can be put forward when dealing with "social costs". These costs refer to the "epistemic" networks the scientist is working in. The literature on invisible colleges has emphasised the positive effects networks have for the diffusion of new ideas. It is, however, not said that "fore-runners" and the scientific elite respectively can maintain their networks once they decide to build up a new scientific field. Again, this may depend on the cognitive distance of the new field with the existing one, in which social networks were created.

If the cognitive distance is relatively high, the migrating scientist may face a loss of existing networks and needs to build up new ones. The transaction costs involved in the establishment of "epistemic communities" are lower the more scientists have already entered the new scientific field. 


\section{Material Costs}

Material costs reflect the investments scientists have to make when exercising research in the new field. Such costs are different from one "science" to another and also from one discipline to the other. Humanities, for example, need little equipment while physicists' research work demands expensive laboratories or research centres. The money and infrastructure needed to do research and the effort it costs to obtain such resources reflect the material costs.

In sum, to leave well-established scientific fields generates costs - cognitive, social and material ones. These costs are part of the decision-making considerations of actors and are set in relation to the benefits expected from migration. In this sense, costs have to be deduced from expected utility.

\section{Probabilities}

The final decision component a researcher has to take into account is the likelihood that investments into a new field can and will be successful or, in other words, that the new field can be institutionalised and serve utility enhancement of the scientist. Such probabilities depend in our view on two context conditions:

First, on the resistance of existing disciplines which might feel threatened in their existence or identity if the new field develops. Such resistance can result in difficulties to create employment and might deter potential scientists in the old field to migrate.

Second, it also needs financial support of key institutions like funding agencies and research organisations that flag out their willingness to invest into the new area. If such a support is lacking, scientists reflecting about migration might not develop the needed trust to leave their own field for an uncertain future.

The estimation of probabilities to succeed or fail will be included in the decision formula by using a factor " $p$ ". P estimates the probability of success if migrating to a new field. There is a probability for success of 1-p if the scientist remains in the existing area. The more factors appear to be negative when estimating the chances of success, the lower the utility of migrating will become. These considerations are expressed in the following formula:

$$
\mathrm{EU}(\text { change })=\operatorname{pnUj}+(1-\mathrm{p}) \mathrm{mUi}-\mathrm{C} ; \quad 0 \leq \mathrm{p} \leq 1 ; \mathrm{C}>0
$$

where $\mathrm{C}$ are the costs and $\mathrm{p}$ the probability.

This formula can then be broken down by simple arithmetic to:

(a) $\mathrm{EU}($ change $)=\mathrm{pnUj}+(1-\mathrm{p}) \mathrm{mUi}-\mathrm{C}>\mathrm{mUi}$

(b) $\mathrm{EU}($ change $)=\mathrm{nUj}-\mathrm{mUi}>\mathrm{C} / \mathrm{p}$

\section{Illustrating the Choice Model}

For the sake of illustration, let us discuss a number of hypothetical but typical cases of choice about scientific migration and interpret them in the light of our choice model. 
1. The most frequent case of building a new field of science is certainly the development of specialties within a discipline or of sub-specialties within a specialty. They are, in the terminology of Bonaccorsi, "divergencies", i.e. new fields that are still united by a common roof, an overarching paradigm, concept or methodology, but which tackle until now unexplored questions and objects. The development of the new field may need adaptation of methodologies and development of new concepts but its establishment usually does not question the fundamentals of the mother discipline/specialty. Examples of such divergencies are abundant. In the social sciences, one could, for example, think of the development of comparative political science within political science, of social psychology within psychology, or of medieval history in historical science.

It seems that the choice of scientists to migrate into these areas when they were in the making is influenced positively by the various decision variables.

If we take pay-offs first, the following can be suggested: Most of the time migration in the case of divergence is "short-term". As a consequence, reputation acquired in the mother discipline or specialty can usually be maintained, while reputation in the new field can be built up gradually. The new reputation is seen as a complement to the already existing one. At the same time, specialisation allows "competitive advantage" for the migrating scientist - at least in the beginning because of the smaller numbers of scientists active in the new field. The chances to increase reputation quickly are better than in the case of staying in the old field. To obtain secure employment in the new field may for quite some time - as long as there is no recognition as a specialty or subspecialty - be difficult but the strong anchorage in the mother discipline/specialty allows continuing to apply for professorships in the broader field and find a stable position. Overall, therefore, payoffs seem to be positive.

The investment into the new field is inspired by, on the one hand, "grievance" about the potential of existing concepts to explain phenomena of interest to the scientist and the discovery of alternative or new concepts or methodologies that seem to better explain these phenomena. Effectiveness of the new field is therefore judged superior to existing explanations but there is still uncertainty and it needs consolidation of the new concepts by research to raise effectiveness substantially (" $n$ ") in comparison to existing explanations ("m").

Consolidating new concepts and methodologies need cognitive investments and raise therefore costs but these costs should be limited as basic anchorage in existing paradigms and concepts remain. Social costs can be considered as being low because links to the mother discipline/specialty remain alive and existing networks will continue to exist while at the same time new ones can be established. Material costs depend completely on the kind of resources that are needed in the new field and can vary.

Probabilities are in principle quite high: Specialty and subspecialty formation do not cause major resistance by scientists in the mother discipline/specialty or adjacent specialties/subspecialties as long as the new field is sufficiently distinct 
in its cognitive orientation. The recognition of common overarching paradigms contributes to the understanding with other specialties and scientists in the mother discipline. Support by funders and research organisations should be available without too much difficulties as the new field is, because of its relative cognitive proximity, seen as a contribution to the development of these already recognised mother disciplines/specialties.

All in all then, one sees that pay-offs and also to a lesser extent effectiveness can easily outweigh "mUi", the expected utility of the existing field, while costs remain limited and probabilities to establish the new area are relatively high. $\mathrm{C} / \mathrm{p}$ is as a consequence small. Migration is therefore likely, as long as we make abstraction of "timing" and "risk profiles", a topic we will discuss within the section on diffusion.

2. Without going into too much detail we can add a special case of divergence, similar in its outlines to the one discussed above but with special characteristics we often find in natural and life sciences.

Imagine a scientific field in which some fundamental questions have been unsolved for quite some time. It is obvious that the answers to these questions will result in high reputation of the scientist giving the answers. The main obstacle, however, is to find adequate methods in order to be able to answer these questions. One can think here, for example, of the development of genomics as a specialty in molecular biology. Molecular biology was able to develop after Watson and Crick deciphered the structure of DNA in 1953. The understanding, however, of the composition of the genome of living beings and in particular of the human genome remained a mystery until new methods (polymerase chain reaction; automated DNA sequencing; the development of computer technology and special software and their use in genome sequencing) were found and implemented. This gave rise to genomics as a new field.

In this case again, scientists embarking on the road of discovery of these methods in order to answer the pertinent questions do not travel long in their conceptual development, which is firmly anchored in molecular biology and they can maintain a large part of their scientific capital acquired in this field. Possible reputation gain is even more promising than in the example above as the new methods promise to find answers to long asked questions (as, for example, the composition of the human genome). In due consequence, resistance to this scientific quest by scientists in the mother discipline is not to be expected. Financial investments were already starting to increase after the DNA structure was deciphered. There was a strong existing interest by funders and research organisation to go further. Overall, probabilities to succeed were therefore high.

The main difference with the previous case are probably the high costs that are involved in this intellectual enterprise. Cognitive costs to learn the new methods were considerable and the sums of money needed for developing the new methods and apply them were substantial. Most important, however, is effectiveness. There are two different phases of development and therefore decision-making in this case: during the first phase there is the search for finding the new methods. The effectiveness of the new field to be developed must still be considered as very low 
as it is very uncertain that the search will be successful. The low " $n$ " reduces " $n U j$ " considerably in relation to "mUi". Once methods became known, effectiveness could become very high. Even the high costs of investment (cognitive, material) could not outweigh anymore the decision of scientists to start to invest into the new area: high reputation was guaranteed for the first movers and support of funders was there. From this point onwards migration to genomics became a very viable option for molecular biologists.

3. Let us, finally, briefly present a negative case for migration in which most decision variables are unfavourable for the decision of scientists to migrate.

Psychoanalysis is a case in point. One can consider Freud's theoretical propositions as an alternative paradigm in the field of psychology and psychiatry, which contested fundamentally - and this has not changed until today - existing paradigms and concepts. The contestation of existing knowledge raised in contrast to the preceding cases a completely different reaction by scientists in the old fields. Resistance to integrate the new field into the university could be expected. A further disadvantage in this respect was also the strong linkage to medical practice and the use of private practice as a place of research. Academic resistance and concomitant lack of support from scientific organisations resulted in low expectations about the possibility of reputation gains when migrating to psychoanalysis as well as about employment possibilities. Under these circumstances it needed very strong "grievance" with existing knowledge and strong intellectual curiosity, as well as a firm conviction that the new field would result in more advanced knowledge, to make scientists move. Unfortunately, demonstrations of effectiveness were and have remained difficult and effectiveness was not helped by the intellectual scissions that followed quickly between Freud and some of his followers. To this can be added that the transaction costs to go into psychoanalysis were particularly high especially because of the long time it took to learn the basics of psychoanalytic treatment.

If we summarise this in terms of our choice model, one sees quickly that $\mathrm{C} / \mathrm{p}$ was for scientists higher than the sum of $\mathrm{nUj}-\mathrm{mUi}$. Reputation and employment prospects in the new field were low and effectiveness doubtful. It needed indeed a strong belief in the explanatory potential and a low weighting of reputation to give an incentive to scientists to reflect migration. In general, remaining in the old area seemed to be more promising. The probabilities to really establish the field in a long-term perspective were low while transaction costs were considerable. The result were low incentives for scientists to invest into the new area. Psychoanalysis has never overcome these deficiencies.

\section{Diffusion}

The next section will address the problem of scientific migration from a different angle. The decision formula developed above is conceived as a decision of individual scientists based on the information available, their expectations and weighting of preferences. To fertilise the grounds of a new scientific field does, 
however, mean that an increasing number of scientists must take the same decision, i.e. to migrate. Diffusion theory has taught us that decisions of scientists may be taken individually but they are not independent of decisions of fellow scientists. Migration can be seen as a collective action problem and one should ask how it is possible that not only one but an increasing number of scientists are willing to work in the new field.

Diffusion theory, as presented for example by Rogers (1995), helps to understand how the process is taking place: innovations take place by following an "S-shaped" curve indicating the number of adoptions during a certain time period. This insight was taken up by the "invisible colleges" literature. While usually the adoption of an innovation - in our case of the decision to migrate - has a slow start with first only a few innovators and then "early adopters", after a certain time a quick rise in numbers is taking place seeing the inflow of "early majorities". When the innovation has become already well-known, the number of adopters coming in decreases considerably ("late majorities" and "late-comers"). If one observes only the number of new adopters coming into the field, the curve by contrast is "bellshaped" with the highest number of new adopters in the mid-term of the innovation and then gradually decreasing in the course of time until no new adopter is found. If one accepts these findings as relevant also for intellectual migration, how can our choice model help to explain this dynamic pattern?

What one can learn from diffusion theory is that, first, time matters: the longer an innovation exists the more the conditions of adoption, or in our case of entry into the new field, vary. Scientists going into the new field in the very beginning face very different conditions than the ones digging for the last available ideas. Second, riskprofiles of adopters and, hence, of scientists are different. Risk-takers advance fast while risk-minimisers will come in very late. Risk-profiles depend on personal attributes but to a large extent also on context conditions. Let us first elaborate the relationship of time, the development of the field and migration.

\section{Time Matters}

There are two variables that change with time. The first one was presented by Holton (1962) when he described new scientific fields as stocks of yet undiscovered ideas that are limited. Early adopters have the best opportunities for discovery while laggards will need to scratch very hard to still make discoveries in this field. Each scientific field has, therefore, its "time" - a period of discovery, exploitation and depletion. If one accepts this as a basic characteristic of intellectual development in scientific fields, this should have implications for the various decision variables of intellectual migration. The second variable refers to the number of scientists active in the field. A few active scientists create a different condition for entry than if there are already a large number exploiting the field.

If we keep these two variables in mind, how do they affect the different components of the choice model?

Effects on the weighting of reputation gain when entering the new field vary in time. This can be best demonstrated by sketching the two curves of development 


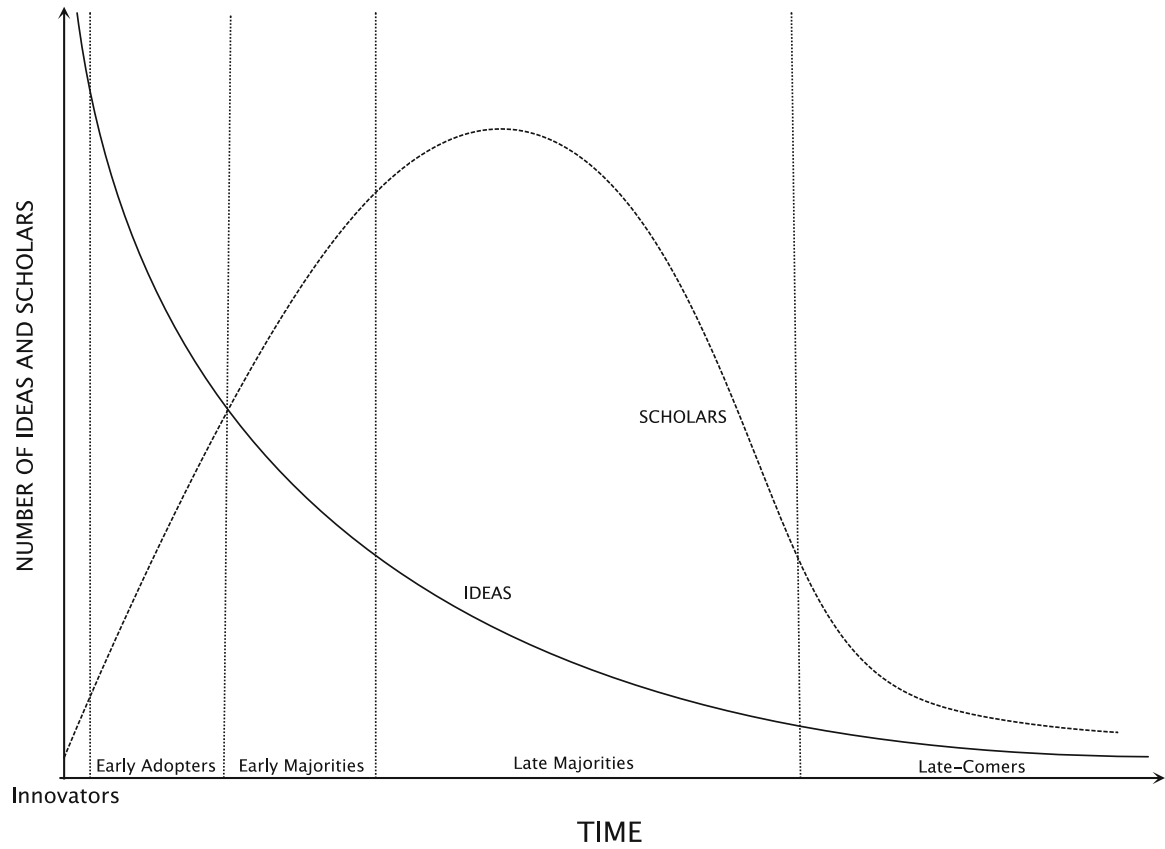

Fig. 1 Development of ideas and scholars in scientific fields over time

of the "stock of ideas" and of the "number of scientists" on a diagram (compare Holton 1962: 389) (Fig. 1).

The implications for reputation are straightforward: The highest reputation can be gained (originality) by innovators or fore-runners who are making the discovery. They are almost alone in the field so that reputation cannot be contested by other scientists and they profit from the originality of their findings. Early adopters will see more scientists next to them entering the field but the numbers are still relatively limited so that the chances to win reputation remain high, especially also because the number of undiscovered ideas is still very high. This begins to change when early majorities and especially when late majorities come in. In the latter case, the field is already crowded by scientists so that one finds high competition for reputation while the number of available unexplored ideas begins to decline considerably. New ideas become a "scarce good". This leads gradually to decisions of several scientists to leave the field and seek for better reputation conditions. The number of scholars starts to decline. Late-comers, finally, have few chances to increase their reputation when entering the field. Though the number of scholars left in the field is now becoming quite small, unexplored ideas will be very hard to find. Reputation chances decline therefore the longer the field exists. They are highest in the beginning but innovators and even early adopters are bearing a high risk that the field cannot be developed and that investments may have been in vain.

Similar considerations can be made for the other components of the decision formula: 
- Resources like employment will be hard to find in the initial period, when few investments are made into the new area. With time and success secure employment positions will increase.

- The effectiveness of the new field increases with time as more and more research will demonstrate the knowledge gain in an increasing number of objects.

- Cognitive costs will probably not sharply decline as most of the time entry into the new area is linked to the learning of new methods, concepts etc. But with time a process of standardisation and communication of knowledge develops that facilitates access to the new field.

- Social costs decline because more and more networks will exist in the course of time where new researchers can be integrated. This does not lower the costs of leaving old networks but integration processes proceed quicker with time.

- Material costs will not change if research needs certain equipment. Costs for such equipment are usually not flexible.

- Probabilities, finally, may increase with time for two reasons: if there has been resistance to the new field by existing disciplines or specialties, such resistance will be more easily overcome by institutionalisation and continuing success. This raises the probability that one can be successful in the new area. In addition, it is likely that more scientific elites are drawn into the area, especially in the period of early adopters and that good research institutes start to invest within the new field. This creates trust in the new area and increases therefore probabilities of success for new adopters.

What does this mean for the choice model?

The timing when to enter a new field has an effect on the value of the variables that constitute the decision formula. This means that also incentives to migrate change with the development of the new field.

In the beginning period with high costs and low probabilities, uncertain resources and effectiveness, the sum of $\mathrm{nUj}-\mathrm{mUi}$ will seldom be larger than $\mathrm{C} / \mathrm{p}$ for most scientists. It needs a certain risk profile, above all linked to "effectiveness", to make the sum higher than the product out of costs and probabilities (see below the risk profiles). At a later stage, reputation gain decreases considerably while costs decline and probabilities increase. Effectiveness and employment prospects increase also. It is therefore above all the weight given to reputation in the new field, which decides about migration in later stages. In the later period under late majorities one sees that the decline of reputation prospects can be judged so low that newly developing fields start to have a better chance to be selected for research.

\section{Risk Profiles}

Rogers introduced different types of adopters. He believed that these groups could be explained by psychological characteristics but also by their social status, education, and social connectedness (Rogers 1995). These criteria seem plausible but are derived inductively rather than deductively, i.e. from the point of view of a theoretical model. The last step in the presentation of our choice model therefore is 
the interpretation of the different "adopter groups" or "risk groups" in the light of the variables that compose the choice model.

\section{Fore-Runners}

Fore-runners or innovators are the first to enter the scientific field and make original discoveries. As the previous section demonstrates, such scientists face considerable costs, lack probably resources, must cope with high uncertainties about effectiveness but have the chance of astounding wins on the reputation side. Their aim is not the building of a new scientific field but of making original discoveries. This limited objective explains why fore-runners can indeed advance without taking too much risk: As they do not intend to construct a new field, they do not need to take probabilities into account and their costs remain relatively low: social costs do not come up as innovators usually maintain their established networks and cognitive costs exist only in the investment to solve the scientific problems they are facing. Material costs may exist in order to finance the necessary experiments etc. In other words, C/p tends to decline to zero. On the other side, one can assume that forerunners are highly motivated by grievances about existing knowledge and that they value new discoveries ("effectiveness") very high. As discoveries are usually made by senior scientists already belonging to the "scientific elite" ("invisible colleges") or are even "stars" (Zuccala and van den Besselaar 2005), they will have a secured employment position. Reputation remains important for fore-runners. Being part of the elite, competition for reputation is particularly intense and only "original" contributions may really create the necessary recognition for these scientists. Risks of failure are also reduced because, as Frickel and Scott suggest (see above), usually one expects them to be weird and try out new ideas. In sum, it is easily to be seen why the decision in favour of "running into no-man's land" can be taken by this particular group. Highly motivated by intellectual curiosity and the need of continuing high reputation gain while risks to fail remain limited and costs low, these scientists strive for originality.

\section{Founders}

Fore-runners may, once the discovery has been made, decide to leave the exploitation of the discovery to others and move on or they may decide to stay and become "founders" (Ben-David 1991: 54).

If they decide to stay, costs in institutionalising the new field will start to matter. Social costs by contrast will usually be low as high-standing scientists will have durable and encompassing networks in their existing working fields. Cognitive costs exist in so far as the new field now has to be explored and adequate concepts need to be developed. Material costs will increase in order to develop the new area. Probabilities must now also be taken into account: it depends if the new field is contesting existing fields and therefore if it creates resistance and if financial resources can be found to support the building process. The person of the founder itself can positively contribute to such a support. 
Founders are, as fore-runners, highly motivated by intellectual curiosity and the intensive search for reputation gain at an already high level of credibility. The difference with the fore-runners consists in their different judgment of where better opportunities lie: fore-runners think that only continuing original contributions can maintain their place in the scientific elite. Founders, by contrast, opt for the elaboration of the new field in order to add to their reputation stock. Their advantage is that they can base their research activities in the new field on the discovery made. " $\mathrm{N}$ " is therefore higher than in the case of the fore-runner who has to deal with considerable uncertainty about effectiveness of his or her investments.

\section{Early Adopters}

Early adopters differ above all from the previous group because they enter into the field after the discovery has been made with the intention of staying there for quite some time. They consider themselves as the "explorers" of the scope, the limits and possibilities of the new field.

This risk group is very much attracted by reputation gains that are still very promising as only fore-runners and founders have until now entered the field. It is very likely that this group, which faces important transaction costs and low probabilities of success, despite first discoveries, has an inferior position in existing fields of science and sees in the new field excellent conditions to accelerate their strife for reputation. It is most likely that these scientists are the "Young Turks" Becher and Trowler mention (Becher and Trowler 2001: 99) or "Juniors" (Zuccala and van den Besselaar 2005) who have "as yet made no major intellectual commitments" and who have "little to lose by investing in potentially high-risk, high-profit commodities" (Becher and Trowler 2001, ibid.). Younger scientists face less loss of social costs and have often still less invested in their previous cognitive field so that transaction costs of migration remain low. Their position is often also not secured which adds to their mobility. Finally, they are often associated to a founder with whom they start their career. This proximity makes it easy to follow the moves of the elite scientists.

Early adopters can gain high reputation as their work - the first exploration of the confines and contents of the new area - can still be considered at least in part as original contributions.

\section{Early Majorities}

This group of scientists is attracted when the first "measurements" in the new field have been made and confines have been defined. The group is important to deepen out the knowledge to confirm or contest it, to build on a common paradigm and, thus, contribute to its development and diffusion. They are the "constructors" Dogan and Pahre have proposed as one of three idealtypes of migrating scientists (Dogan and Pahre 1990: 223). Their reputation prospects are more moderate than in the case of the first groups as originality is by now gone and there are a larger number of competitors struggling for credibility. On the other side, effectiveness of 
the new field is becoming more visible, research money is more easily available and social costs decrease with the larger number of scientists now entering the field. Transaction costs are, nevertheless, still high and probabilities remain moderate as it is up to these scientists to prove the worthiness of long-term investments into the field. Scientists in this group are probably, as Becher and Trowler suggest (p. 95), "disenchanted with their current line of research - usually because it is, or they themselves are, apparently going stale - and who are therefore looking out for promising fresh departures". Another obvious reason are decreasing reputation chances in the old field because of depletion and/or a high number of competitors. This group of scientists usually has already some achievements and some reputations but is still eager to become part of "upper class" in science or even of the elite group. They are still "hungry" enough to be constantly on the lookout for new opportunities. However, they have more to lose than the Young Turks when migrating to new fields because of existing social networks and already considerable investments in existing cognitive areas. They may also have already secure employment positions while the new field can still create uncertainty about future employment prospects.

\section{Late Majorities}

This risk group is not anymore motivated by reputation gain. They are the "followers", as Fuchs has defined them (Fuchs 1993), who see above all a chance to secure "material advantages" when migrating. And at this stage of diffusion, resource prospects have become clearer and more advantageous than in the beginning as already a considerable number of scientists is working in the field and has gathered research money or even employment positions in public research organisations. Infrastructure will be built up. There are still improvements to be made - and the late majorities are above all there to consolidate the new field by standardisation of the findings; they are not exploring but are now furnishing the "house" in order to make it comfortable - so that resources will keep flowing in and these scientists have a chance to improve their position. Late majorities are not risk-prone, on the contrary. They like transaction costs to be minimised and need higher probabilities that the field will continue to exist in order to migrate. Their social status in the old field will usually not be very high and they lack the aspiration of still moving up the career ladder.

\section{Late-Comers}

Late-comers, finally, come into the field when many other scientists have already left to explore new fields. They leave their old field mostly because most others have already done so before. They are not interested in "innovation" or in "exploring", "constructing" or "consolidating". Their task is to participate in the elaboration of the last remaining questions or help to vulgarise the new area. They are very riskaverse. In their decision-making, the decrease of employment chances in the old field is the most significant reason for migration, which raises the chances of scientific survival in the new area. 


\section{Conclusions}

The intention of this article was to improve our understanding of the reasons underlying the intellectual migration of scientists from well-known cognitive domains to nascent scientific fields. To that purpose we presented, first, a number of findings from the sociology of science that give different insights about this phenomenon. We then attempted to bring some of these insights together under the conceptual roof of an actor-based approach linking expected utility and diffusion theory. Intellectual migration is regarded as the rational choice of scientists who decide under uncertainty and on the base of a number of decision-making variables, which define probabilities, costs, and benefits of the migration.

Diffusion theory was used to demonstrate the typical dynamics of the migration process in science. We endeavoured to link the insights of diffusion theory to decision-making variables and identified different types of scientists who could fit into the categorisation of actor groups diffusion theory has developed, i.e. "innovators", "early adopters"; "early majority", "late majority" and "late-comers".

We believe that modelling decision-making of scientists has the advantage of identifying, as Kitcher explains (Kitcher 1995), relevant variables and their causal interrelationships. This permits to formulate reasoned expectations under what conditions scientists will engage into certain behaviour. The usefulness of such a model is therefore in its heuristic value: it permits to focus on those variables that have been identified in the literature as probable explanations of migration behaviour and suggest interaction effects between them. The decision-making formula itself can then be an instrument to define expectations and hypotheses about the behaviour of scientists.

This does not mean that institutions and structures would not matter. They do. But they are seen as exogenous factors that create incentives or disincentives for scientists and influence their estimations about the various decision-making variables. The relationship of institutions and structures and scientists' decisions about migration must be elaborated further. In this article, it was important to develop the micro-foundation of scientific behaviour. Future research should take these insights as a starting point and test to what extent the development of new scientific fields can be explained in terms of decision-making rationales of scientists and follow the diffusion dynamics of innovation processes.

\section{References}

Åkerlind, Gerlese S. 2008. An academic perspective on research and being a researcher: an integration of the literature. Studies in Higher Education 33(1): 17-31.

Becher, Tony, and Paul R. Trowler. 2001. Academic Tribes and Territories: intellectual enquiry and the cultures of disciplines. Open University Press/SRHE.

Ben-David, Joseph. 1965. Scientific Productivity and Academic Organization in Nineteenth Century Medicine. In Science and society, ed. Norman Kaplan (Hrsg.), 39-62. Chicago: Rand McNally \& Company.

Ben-David, Joseph. 1991. Social Factors in the Origins of a New Science. In Joseph Ben-David. Scientific growth, ed. Gad Freudenthal, 49-69. Berkeley: University of California Press. 
Bloor, David. 1976. Knowledge and social imagery. Chicago: Chicago University Press.

Bonaccorsi, Andrea. 2007. Explaining poor performance of European science: Institutions versus policies. Science and Public Policy 34(5): 303-316.

Bonaccorsi, Andrea. 2008. Search regimes and the industrial dynamics of science. Minerva 46(3): $285-315$.

Bourdieu, Pierre. 1975. The specificity of the scientific field and the social conditions of the progress of reason. Social Science Information 14(6): 19-47.

Braun, Dietmar. 2003. Lasting tensions in research policy-making: A delegation problem. Science and Public Policy 30(5): 309-322.

Braun, Dietmar, and Fabrizio Gilardi. 2006. Taking 'Galton's problem' seriously. Towards a theory of policy diffusion. Journal of Theoretical Politics 18(3): 298-322.

Chubin, Daryl E. 1976. The conceptualization of scientific specialties. Sociological Quarterly 17(4): 448-476.

Clark, Burton C. 1995. Complexity and differentiation: the deepening problem of university integration. In Emerging patterns of social demand and university reform: through a glass darkly, eds. David Dill, and Barbara Sporn. Oxford: IAU press/Elsevier.

Crane, Diana. 1972. Invisible colleges. Chicago: Chicago University Press.

De Solla Price, Derek J. 1963. Little science, big science. New York: Columbia University Press.

De Solla Price, Derek J. 1971. Some remarks on elitism in information and the inviable college phenomenon in science. American Society for Information Science Journal 22(2): 74-75.

Dogan, Mattei, and Robert Pahre. 1990. Creative marginality. Innovations at the intersection of science. Boulder, Colorado: Westview Press.

Edge, David. 1990. Competition in modern science. Solomon's House Revisited. Science History Publications. Canton MA:208-32.

Esser, Hartmut. 1993. The rationality of everyday behaviour. A rational choice reconstruction of the theory of action by Alfred Schütze. Rationality and Society 5(1): 7-31.

Frickel, Scott, and Neil Gross. 2005. A general theory of scientific/intellectual movements. American Sociological Review 70(2): 204-232.

Fuchs, Stephan. 1993. A sociological theory of scientific change. Social Forces 71(4): 933-953.

Holton, Gerald. 1962. Scientific research and scholarship notes toward the design of proper scales. Daedalus 91(2): 362-399.

Kitcher, Philip. 1995. The advancement of science: Science without legend, objectivity without illusions. Oxford University Press, USA.

Kogan, Maurice. 2000. Higher education communities and academic identity. Higher Education Quarterly 54(3): 207-216.

Kuhn, Thomas S. 1968. The history of science. In International Encyclopedia of the Social Sciences, Vol. XIV, ed. David S. Sills (Hrsg.), 74-83.

Lamont, Michèle. 2010. Looking back at Bourdieu. In Cultural Analysis, and Bourdieu's Legacy, eds. Elizabeth Silva and Alan Warde, 128-141. Abingdon and New York: Routledge.

Latour, Bruno, and Steve Woolgar. 1979. Laboratory life. The social construction of scientific facts. London: Sage.

Manathunga, Catherine (2009) Post-colonial perspectives on interdisciplinary researcher identities. In Academic research and researchers, eds. Angela Brew and Lisa Lucas, 131-45. Maidenhead: Open University Press, MacGraw Hill.

Rogers, Everett M. 1995. Diffusion of innovations. New York: McMillan.

van den Daele, Wolfgang. 1977. The Social Construction of Science: Institutionalisation and Definition. In The Social production of scientific knowledge, eds. Everett Mendelsohn, Peter Weingart and Richard Whitley, 27-54. Dordrecht: Reidel Publishing.

Weingart, Peter. 1997. From "Finalization" to "Mode 2": old wine in new bottles. Social Science Information 36(4): 591-613.

Whitley, Richard. 2000. The intellectual and social organization of the sciences. Oxford University Press, USA.

Zuccala, Alesia, and Peter van den Besselaar. 2005. Modelling the invisible college. Journal of the American Society for Information Science and Technology 57(2): 152-168. 